\title{
Road Deformation Monitoring and Event Detection using Asphalt-embedded Distributed Acoustic Sensing (DAS)
}

\author{
Peter G. Hubbard ${ }^{1}$, Ruonan Ou ${ }^{1, \mathrm{C}}$, Tianchen $\mathrm{Xu}^{1}$, Linqing $\mathrm{Luo}^{2}$, Hayato Nonaka ${ }^{3}$, Martin \\ Karrenbach $^{4}$, Kenichi Soga ${ }^{1}$ \\ ${ }^{1}$ University of California, Department of Civil and Environmental Engineering, Berkeley, CA, \\ USA \\ C Email: ouruon@berkeley.edu Address: 408 Davis Hall, Berkeley, CA 94720 \\ ${ }^{2}$ Lawrence Berkeley National Laboratory, Berkeley, CA, USA \\ ${ }^{3}$ Kajima Corporation, Tokyo, JP \\ ${ }^{4}$ Optasense Inc., Brea, CA, USA
}

\begin{abstract}
Distributed acoustic sensing (DAS) is a new technology that is being adopted widely in the geophysics and earth science communities to measure seismic signals propagating over 10's of kilometers using an optical fiber. DAS uses the technique of phase-coherent optical time domain reflectometry $(\varphi-O T D R)$ to measure dynamic strain in an optical fiber as small as $n \varepsilon$ by examining interferences in scattered light. This technology is opening a new field of research of examining very small strains in infrastructure that can be indicative of performance and use level. In this study, a fiber optic strain sensing cable was embedded into an asphalt concrete test road and spatially distributed dynamic road strain was measured during different types of loading. It is demonstrated that $\varphi$-OTDR can be used to quantitatively measure strain in roads associated with events as small as a dog walking on the surface. Optical frequency domain reflectometry (OFDR), a widely implemented but less accurate distributed fiber optic strain monitoring technology, is used along with traditional pavement strain gauges and 3D finite element modeling to validate the $\varphi$-OTDR pavement strain measurements. After validation, $\varphi$-OTDR strain measurements from various events are presented including a vehicle, pedestrian, runner, cyclist and finally a dog moving along the road. This study serves to demonstrate the deployment of $\varphi$-OTDR to monitor roadway systems.
\end{abstract}

Keywords: Distributed Acoustic Sensing, Distributed Fiber Optic Sensing, Smart Infrastructure, Instrumentation, Pavement 


\section{Introduction}

Distributed acoustic sensing (DAS) provides a spatiotemporal profile of vibration of an optical fiber. ${ }^{1}$ DAS measurements are the result of changes in optical fiber length on the order of nanostrain or even smaller. ${ }^{2,3}$ Such small perturbations can be used to turn an optical fiber into a distributed vibration sensor, where the elongations at different positions of the fiber are caused by qualitative disturbances in the vicinity of the fiber. ${ }^{4,5}$ To measure the actual movements, a special DAS technique called phase-sensitive optical time domain reflectometry ( $\varphi$-OTDR) is used. ${ }^{6,7} \varphi$ OTDR is a distributed interferometer that uses the natural light scattering within an optical fiber to measure the optical path length change over a length of fiber, called the gauge length. $\varphi$-OTDR has been used for geophysics applications such as monitoring of oil and gas wells. ${ }^{8}$ It has also been used by the scientific community for seismology and geophysical imaging of the near subsurface. ${ }^{9}$

The change in optical path length measured by $\varphi-O T D R$ is proportional to strain in an optical fiber over a single gauge length using the following equation:

$\varepsilon=\frac{\lambda}{4 \pi n G \xi} d \varphi$

where $d \varphi$ is the change in optical path length in radians, $\lambda$ is the operational optical wavelength in vacuum, $n$ is the refractive index of the sensing fiber, $G$ is the gauge length of the $\varphi$-OTDR system, and $\xi$ is the photoelastic scaling factor. ${ }^{10}$

Although $\varphi$-OTDR has not typically been used for quantitatively measuring strain because of low frequency noise in the measurements caused by laser phase drift ${ }^{11}$, this can be mitigated by using digital signal processing methods and examining dynamic strain change. If the phase change value can be evaluated accurately, a $\varphi$-OTDR system can become a distributed strain measurement system that has thousands of sensing gauge lengths along a single optical fiber measured simultaneously at extremely fast rates (10's-100's of kHz).

This study demonstrates how $\varphi$-OTDR can be used for monitoring roadway activities. The recent studies have focused on qualitative evaluation of roadside $\varphi$-OTDR data obtained from unused roadside telecommunications fiber (called dark fiber) to monitor vibrations caused by vehicles. ${ }^{12}$ For example, Liu et al. (2020) showed that DAS data from a roadside array can be used to classify vehicles based on their acoustic signatures. ${ }^{13}$ Lindsey et al. (2020) explored the mechanics that cause the signals at low frequency, identifying the source of $<1 \mathrm{~Hz}$ signals as roadbed strain. ${ }^{14}$ The strain measurements in that study were used to observe the vehicle size, speed, and direction.

For measurements to be used to describe the mechanical behavior of a road, the sensing element must be physically coupled to the infrastructure. This is achieved by coupling an optical fiber within a cable that transfers strain, and then attaching that cable to the infrastructure of interest. Cable design and external coupling for fiber optic strain sensing in geotechnical applications has been a recent topic of research. ${ }^{15}$ Different fiber optic sensing technologies have been used to measure strain in infrastructure including pipelines, tunnels, retaining walls and piles. ${ }^{16-19}$ This study deploys a strain sensing cable ${ }^{15,20}$ to monitor dynamic strain inside an asphalt concrete (AC) test road. The study follows on from our recent work on the use of $\varphi$-OTDR for civil structural 
health monitoring. For example, the technology was used to measure dynamic strain in a model wind turbine tower under dynamic loading. ${ }^{21}$

\section{Monitoring of strain in pavement}

AC makes up $98 \%$ of the paved public road surfaces in the United States. ${ }^{22}$ AC is created by mixing coarse and fine aggregates with heated bituminous binder. The heated mixture can then be laid and compacted in place to create a low-cost, rapidly constructed road surface that provides a comfortable and quiet ride for vehicles. To make a road surface, AC is typically placed on top of a base layer of engineered material underlain by the compacted natural subgrade. There may also be a subbase layer added depending on the environment and design purpose of the pavement system. $^{23}$

Pavement systems have been traditionally designed using empirical methods stemming from data measured at the AASHTO test road in late 1950's. ${ }^{24}$ Recently, there has been a shift towards using a mechanistic-based method for pavement design. This method is known as mechanistic-empirical (ME) pavement design. ${ }^{25} \mathrm{ME}$ design is based on the desired performance of the road. Performance parameters include stresses, strains, and deflections that the road is expected to experience during its lifetime. Roadway performance evaluation is an important part of ME pavement design. Instruments like the falling weight deflectometer (FWD) are used to measure the actual behavior of pavements to assess if they need to be remediated or replaced. This performance-based design approach has opened the door for structural health monitoring (SHM) of pavements. SHM in combination with ME design methodologies can be used to validate design parameters and monitor pavement performance over time.

SHM of pavements has been researched extensively over the last three decades. Techniques include visual examination for surface manifestation of damage and mechanical behavior measurement using in-situ sensors. Surface monitoring technologies naturally evolved from the process of visual inspection of pavements to identify types of damage including cracking, rutting and permanent deflections. ${ }^{26}$ These technologies include computer vision techniques to examine images and classify damage. ${ }^{27}$ On the other hand, in-situ sensors have been tested to measure pressure, strain, temperature, and moisture inside pavement systems. ${ }^{28}$

Of particular interest to this study is previous research on monitoring in-situ mechanical behavior of pavements in the longitudinal road direction under dynamic loading. Since the longitudinal strain at the bottom of the AC layer has been used historically to evaluate pavement design ${ }^{29}$, the typical embedment position of sensors is at this level. For example, in Zafir et al. (1994), strain gauges were installed at the bottom of an asphalt layer (depth of $150 \mathrm{~mm}$ ) to measure strain under the moving load from a semi-tractor-trailer truck. ${ }^{30}$ Bayat et al. (2012) also embedded strain gauges at the bottom of an asphalt layer (depth of $185 \mathrm{~mm}) .{ }^{31}$ Both test results showed that the pavement experienced a compression-tension-compression spatial strain variation in the longitudinal direction under an axle load.

More recent work shows pavement strain data at shallower levels. Gokhale et al. (2009) measured vehicle induced strain at different levels of a pavement system. ${ }^{32}$ It was shown that the pavement experienced longitudinal compression close to the surface (at a depth of $127 \mathrm{~mm}$ ), whereas the 
strains at a deeper level (for example, $381 \mathrm{~mm}$ ) were in tension. Kara De Maeijer et al. (2018) measured the strain response of pavement at depths of 30,70, and $120 \mathrm{~mm}$ under loading from a paving machine. ${ }^{33}$ The test results showed that the pavement exhibited a tension-compressiontension strain variation in the longitudinal direction at the 30 and $70 \mathrm{~mm}$ depths, whereas a compression signature was seen at the $120 \mathrm{~mm}$ depth. The magnitude of compression observed at the $70 \mathrm{~mm}$ depth was smaller than that at the $30 \mathrm{~mm}$ depth, indicating that the pavement system is expected to exhibit a maximum longitudinal compressive strain toward the top surface right under the applied load.

Mustafa et al. (2021) was the first to demonstrate the feasibility of a distributed fiber optic sensing technology called optical frequency-domain reflectometry (OFDR) to measure longitudinal strains when embedded within pavements. ${ }^{34}$ Fiber optic sensing cables were installed at 10, 20 and 40 $\mathrm{mm}$ depths within AC. Results showed that the $10 \mathrm{~mm}$ embedment depth was preferred for maximum sensitivity to a tension-compression-tension spatial strain variation under localized surface loading. Although OFDR can measure strain at extremely high spatial resolution, the coverage length is less than $50 \mathrm{~m}$. Therefore, at present, an OFDR technology is not suitable for practical road application. In this study, however, short-range ODFR data set was used as a verification tool for the longer range, and more sensitive $\varphi$-OTDR measurements.

\section{Experimental Setup}

Fiber optic strain sensing cables were installed in a roadway at UC Berkeley's Richmond field station. The cable used was model NZS-DSS-C02 manufactured by NanZee Sensing Technology. The cross section is shown in Fig. 1. The optical fiber is coated with a tight buffer that adheres to the cladding of the fiber. The buffered fiber is then wrapped tightly between steel braids, locking it in place within the cable. The steel braids are coated with a rugged polyethylene sheath that has a helical grooving on its inside surface to align with the steel braids and prevent translation at the internal interface. Embedding fiber optic sensing cables into Portland cement concrete (PCC) has been demonstrated successfully for monitoring several different types of structures. ${ }^{35-36} \mathrm{AC}$ is a composite material that is made from aggregates and binder, similarly to PCC. In the case of PCC, the binder is Portland cement, while in AC the binder is bitumen. AC is usually manufactured using the hot-mix technique where the binder is heated to a high temperature before mixing in the aggregates. This is referred to as hot-mix-asphalt (HMA). HMA is mixed at a temperatures above $120^{\circ} \mathrm{C}$ and placed shortly after manufacturing. The low-density polyethylene used to make the NZS-DSS-C02 cable's sheath melts at approximately $110^{\circ} \mathrm{C}$. This is expected to increase coupling with the cable and $\mathrm{AC}$ by allowing the cable to be melted in place. The largest construction concern for embedding sensing cables into the road is that $\mathrm{AC}$ is constructed in thin layers that are compacted significantly with industrial equipment. The compaction process poses the largest risk to the cables, so in this study a method of protecting the cables for paving was important. In addition to the fiber optic cables, Wheatstone bridge resistance strain gauges (PMFLS-60-5010LTSC) manufactured by Tokyo Measuring Instruments Lab Co. were installed to verify the fiber optic measurements. The strain gauges were designed specifically for embedment into pavement. 


\section{NZS-DSS-C02 strain sensing fiber optic cable}

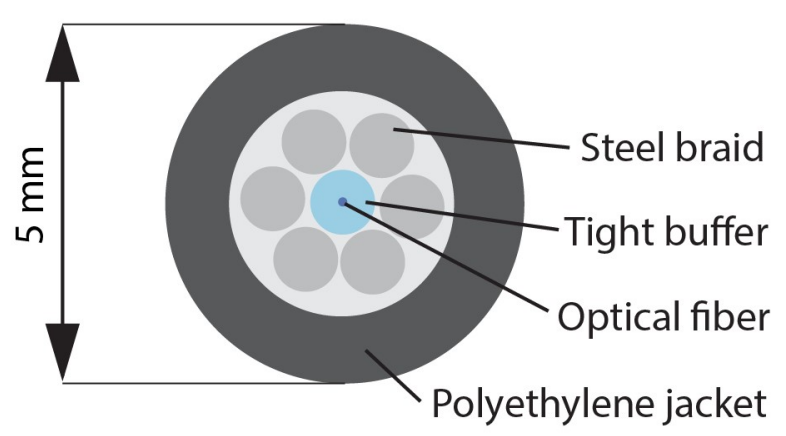

Figure 1. Cross section of NZS-DSS-C02 strain sensing cable. The cable has a tight buffered optical fiber that is wrapped within helically wound steel braids. The steel braids are then tightly contained within a rugged polyethylene sheath. The cable has an outer diameter of $5 \mathrm{~mm}$.

The installation site was an existing road originally paved in 2004 and resurfaced in 2007. Fig. 2 (top) shows aerial photographs of the road site after the fiber optic cables and pavement strain gauges were installed on the existing surface and the road after paving, whereas Fig. 2 (bottom) shows two schematic drawings showing the horizontal and vertical locations of the fiber optic cables and typical strain gauges within the completed pavement. The road was moderately degraded at the beginning of the study, with longitudinal fatigue cracking having occurred over the length. The cracking was caused by $\mathrm{AC}$ fatigue of the existing overlay. The road was constructed of $200 \mathrm{~mm}$ of cohesive subgrade, $395 \mathrm{~mm}$ of aggregate base (AB) class II, and $51 \mathrm{~mm}$ of AC, as shown in Fig. 2 (bottom). A new overlay was to be placed over top of the existing road surface, and an installation of fiber optic cables below the new overlay was designed. The new overlay was $31.75 \mathrm{~mm}$ of AC placed directly on top of the existing $51 \mathrm{~mm}$ thick AC. 


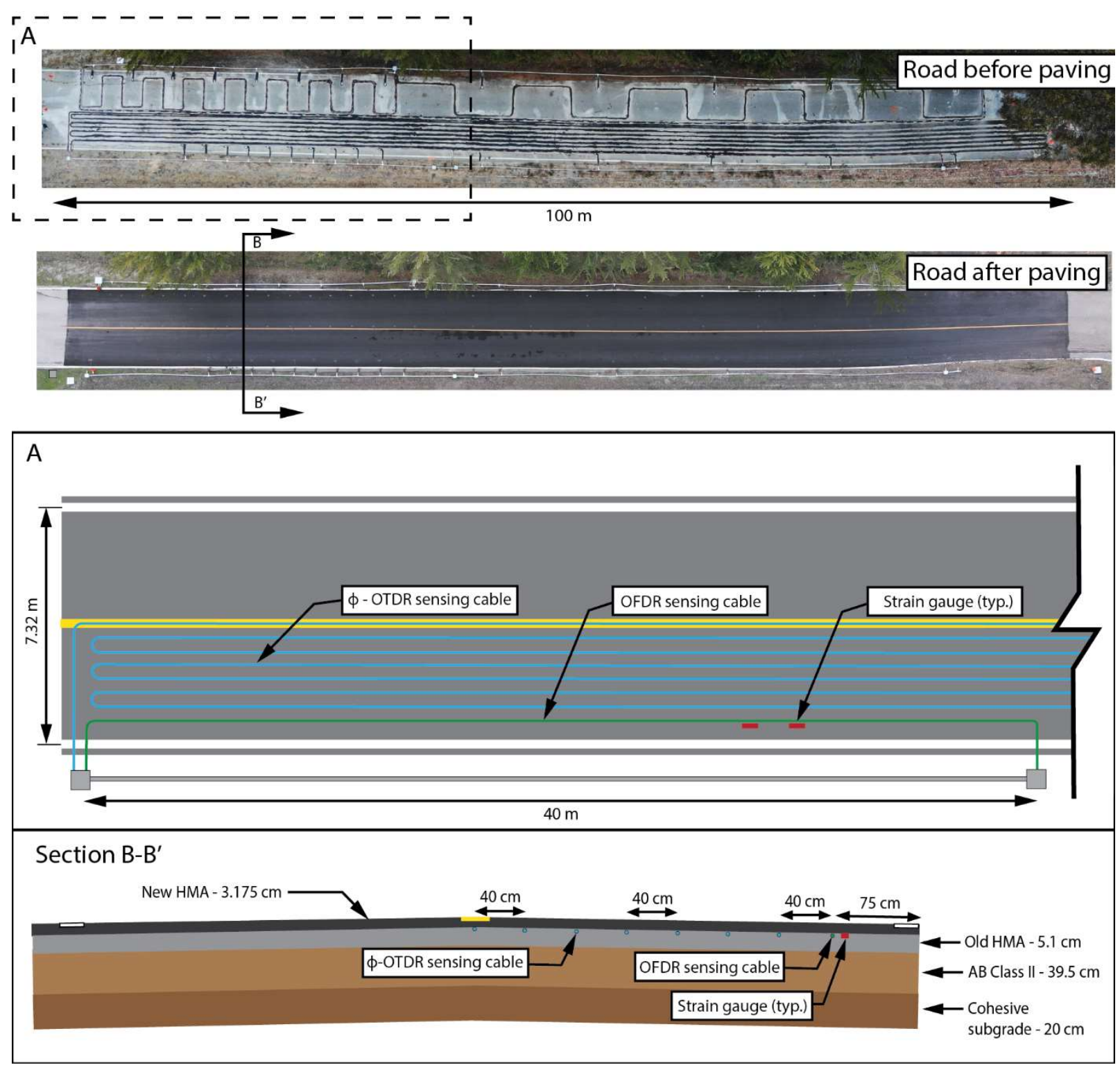

Figure 2. Aerial photographs of the road before and after paving with schematic diagrams of the fiber optic cable locations. Two lengths of NZS-DSS-C02 cable were installed into the pavement for this study. $40 \mathrm{~m}$ of cable was used for OFDR, while approximately $700 \mathrm{~m}$ was used for $\varphi-O T D R$ due the difference in sensing range between the technologies. The $\varphi$-OTDR cable snaked back and forth along the length of the test road with each longitudinal line being $40 \mathrm{~cm}$ apart. Resistance strain gauges (PMFLS-60-50-10LTSC) were installed approximately $5 \mathrm{~cm}$ from the OFDR cable. After the cables were attached to the road surface the road was paved over to fully encase the cables and strain gauges into the road.

Fig. 3(a-f) shows the multi-step process of how the fiber optic strain sensing cables were installed into the roadway. First (3(a)) the location of where the cables would go was marked on the road using marking paint. Next (3(b)), 5 mm-deep grooves were cut into the surface using a pavement 
saw. Fiber optic sensing cables were laid into the grooves and secured using tape (3(c)). Using a mixture of asphalt emulsion and sand, the groves containing the cables were covered for protection during paving (3(d)). A tack-coat was applied to the surface (3(e)), and the road was paved using standard procedures which included placement of asphalt and vibro-compaction of the new surface (3(f)). The strain gauges were installed by using an angle grinder to remove $5 \mathrm{~mm}$ deep rectangle of the existing road surface. The strain gauges were then placed in the cut-out area and capped over with asphalt emulsion and sand. They can be seen to the left of Fig. 3(d).
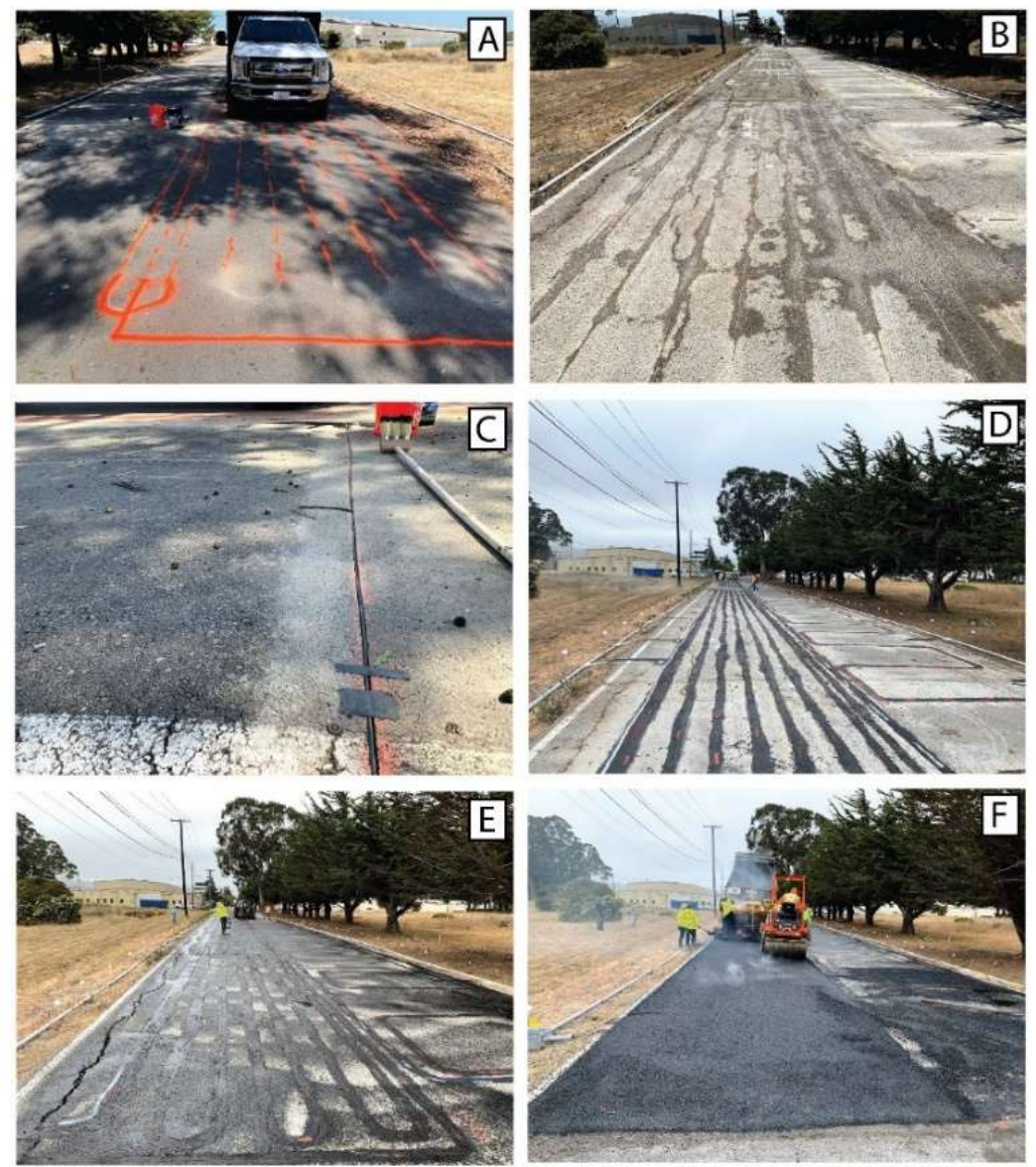

Figure 3. The fiber optic sensing cable installation procedure consisted of (a) marking the locations of the cables on the existing road surface with marking paint, (b) cutting grooves into the pavement surface $5 \mathrm{~mm}$ deep with a pavement saw, (c) laying the NZS-DSS-C02 sensing cable into the grooves and securing temporarily with tape, (d) applying a mixture of asphalt emulsion and sand to the top of the grooves to protect the cables, (e) applying a tack coat to the entire road surface and (f) paving the surface using the standard procedure including placing the HMA with a paving machine and vibro-compacting it.

In this study, two distributed fiber optic strain measurement systems (OFDR and $\varphi$-OTDR) were used. For OFDR, a Luna Innovations ODiSI 6000 with a spatial resolution of $2.6 \mathrm{~mm}$, an acquisition rate of $10 \mathrm{~Hz}$ and a maximum sensing distance of $50 \mathrm{~m}$ was used. The $\varphi$-OTDR system 
used was an Optasense ODH4 with a gauge length of $2.04 \mathrm{~m}$, an acquisition rate of $32 \mathrm{kHz}$ and maximum sensing distance of $10 \mathrm{~km}$.

Although the same fiber optic cable can be used interchangeably with different DFOS technologies, separate cables were installed so that the readings made at the same time by different technologies could be compared. As previously mentioned, OFDR can only operate over a limited length. A $40 \mathrm{~m}$ cable was installed specifically for this purpose and is shown in green in Fig. 2. $\varphi$ OTDR can operate over a much longer distance, so it used a cable that is continuous over $700 \mathrm{~m}$ snaking back and forth in one lane. The specifics of the box-shaped installations in the right lane of Fig. 3(d) are not discussed in this paper and will be reported in the future.

The paving process was observed in real-time using the $\varphi$-OTDR system. The data presented in Fig. 4 is the frequency band extracted (FBE) power in the 17-100 Hz range during the paving process. This type of FBE data display is common for DAS and referred to as a waterfall diagram. It is generated by taking the short-time Fourier transform of each readout channel and plotting the power in a specific frequency range as a pixel color. Fig. 4 shows a mirrored repetition of similar data 7 times. Each repetition corresponds to a length of fiber optic cable stretching the length of the road as shown in Figs 2 and 3d. Two distinct construction phases are shown at the top of Fig. 4. In the first phase, the paver just completed paving the very beginning of the road, while an asphalt truck is backing down the road to refill the paving machine. The second phase is the paving machine and asphalt truck moving together as the paving progresses while a vibratory compactor moves forward and backwards compacting the asphalt. The events can clearly be observed by examining the waterfall plots generated from the $\varphi$-OTDR data. In addition to the movement and location of the construction vehicles on the surface, the activities of the vibratory compactor can be seen in detail. Large power is exhibited in the FBE data when the vibration is on. Visualizing data in both space and time is important for the later parts of this work and this data is displayed as an introduction. Fig. 4 shows data in terms of frequency band power, but the pixels can be other information such as strain, which is explored in the next sections. 


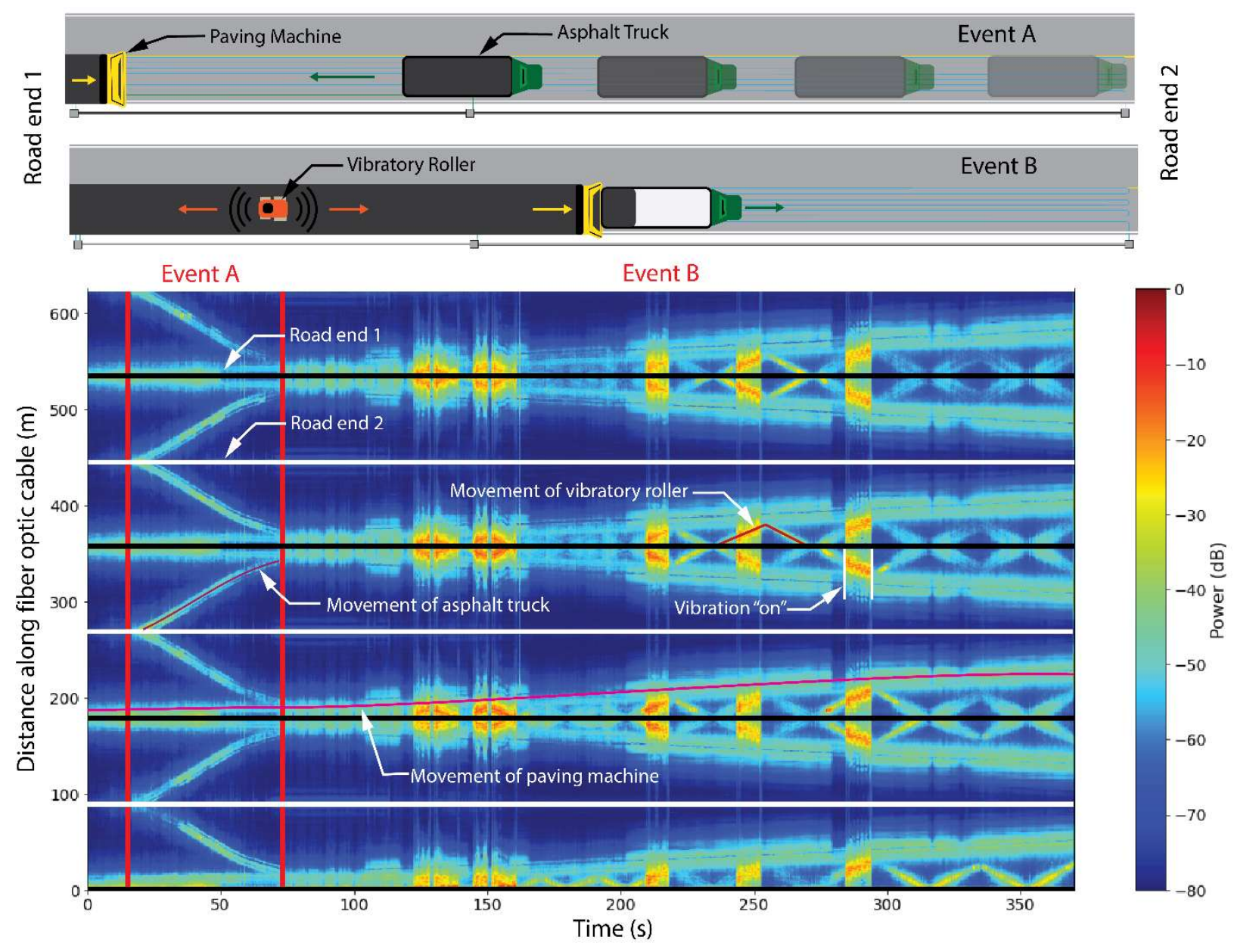

Figure 4. Schematic diagrams of the paving phases and corresponding $\varphi$-OTDR 17-100 Hz frequency band extracted data. The different events that occurred on the road are labeled on the FBE plot including movement of the vibratory roller, movement of the asphalt truck and movement of the paving machine.

\section{Precision error evaluation}

\section{OFDR Instrumentation}

A typical time-series and power spectral density (PSD) of the OFDR data produced by the road instrumentation when no events are happening on the road surface is shown in Fig. 5. The data exhibits a statistical repeatability, as quantified by the standard deviation of 30 seconds of time measurements acquired at $10 \mathrm{~Hz}$ of $\pm 2 \mu \varepsilon$. The average noise floor shown in the PSD plot is $0.3 \frac{\mu \varepsilon}{\sqrt{\mathrm{Hz}}}$ . A time series of the sort shown in Fig. 5 is generated every $2.6 \mathrm{~mm}$ along the sensing cable within the road. This creates a matrix of data where one dimension is indexed by the time interval of 0.1 $\mathrm{s}$, and the other dimension is indexed by the physical spacing. Although OFDR has a relatively high noise floor as compared to $\varphi$-OTDR (see the next section), its naturally flat frequency 
response (requiring no post-processing) and high spatial resolution make it a useful technology for verifying measurements made with $\varphi$-OTDR.
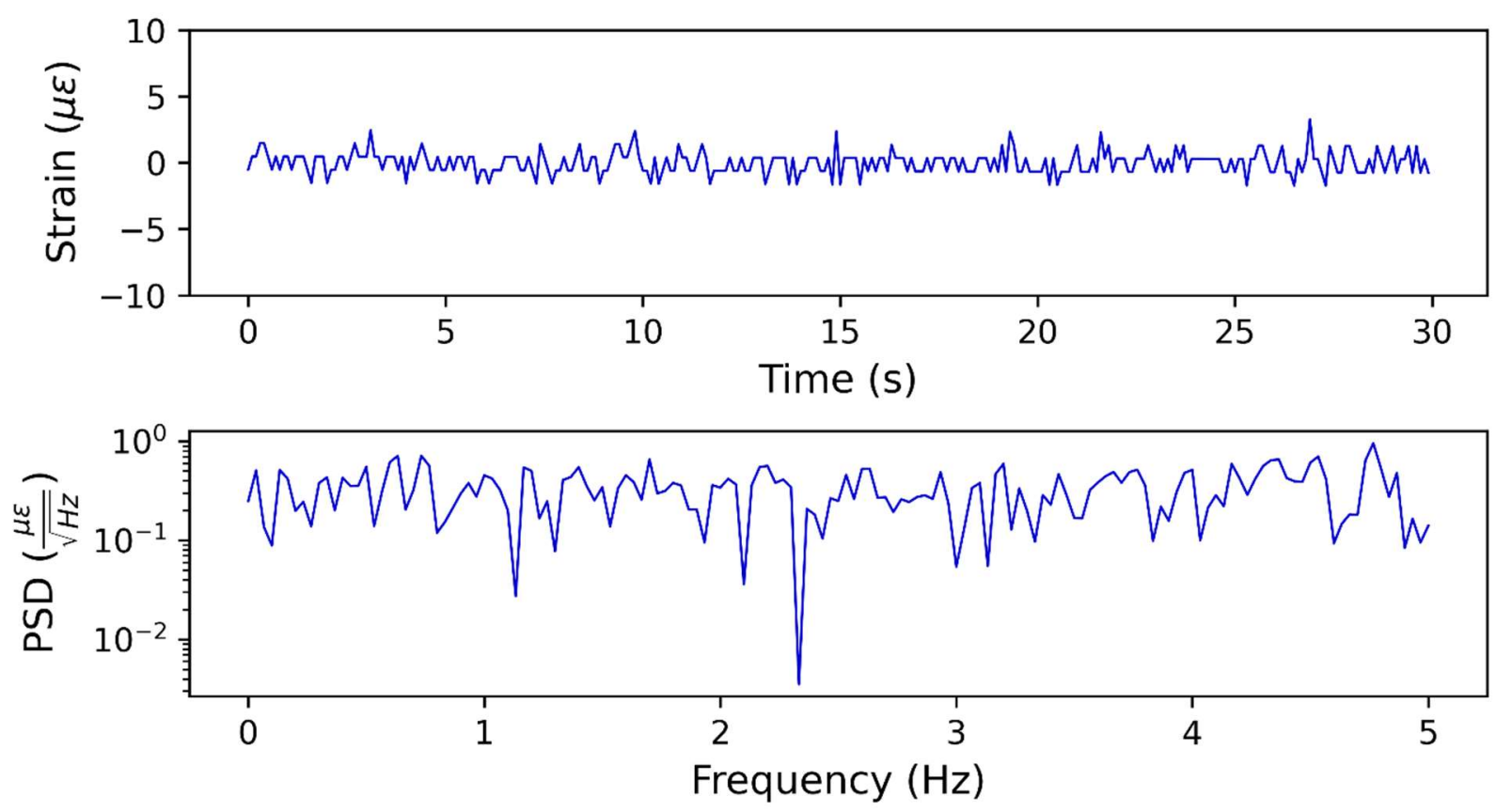

Figure 5. Time-series and power spectral density plots of 30 seconds of OFDR data acquired from within the pavement at the sampling rate of $10 \mathrm{~Hz}$ when nothing is happening on the road surface.

\section{$\varphi-O T D R$ Instrumentation}

The largest challenge of making quantitative strain measurements with $\varphi$-OTDR is its inherent drift at low frequencies known as phase drift. Phase drift is the change in the measured phase of the returning backscatter caused by laser-wavelength drift and cumulative phase noise. ${ }^{37}$ It is particularly a challenge for the monitoring of civil infrastructure with $\varphi$-OTDR because the frequencies of interest are often low. While acoustic signals vary from tens of hertz to tens of kilohertz, structural dynamic strains are usually less than $10 \mathrm{~Hz}$ and extend to DC $(0 \mathrm{~Hz}) \mathrm{when}$ strains are static. Since phase drift manifests as a meandering DC offset in the $\varphi$-OTDR data, digital signal processing techniques need to be employed that eliminate the drift while leaving the lowest possible frequency components of the strain signal unaltered. For roadway monitoring, vehicles move, and events happen dynamically. Even very slow-moving events still manifest as dynamic strains that can be recovered by digitally filtering the data. Reducing phase noise in $\varphi$ OTDR measurements is an active research area. For instance, there have been patents filed that claim to eliminate this problem altogether through hardware developments. ${ }^{38}$

Fig. 6 shows strain measurements and the associated PSD made by $\varphi$-OTDR when nothing is on the road surface. This can be considered a measure of the environmental and systemic noise 
characteristics of the configuration. The phase drift manifests as a drifting of the strain measurements. In this case, the measured strain drifts by $0.08 \mu \varepsilon(80 \mathrm{n} \varepsilon)$ over 30 seconds.
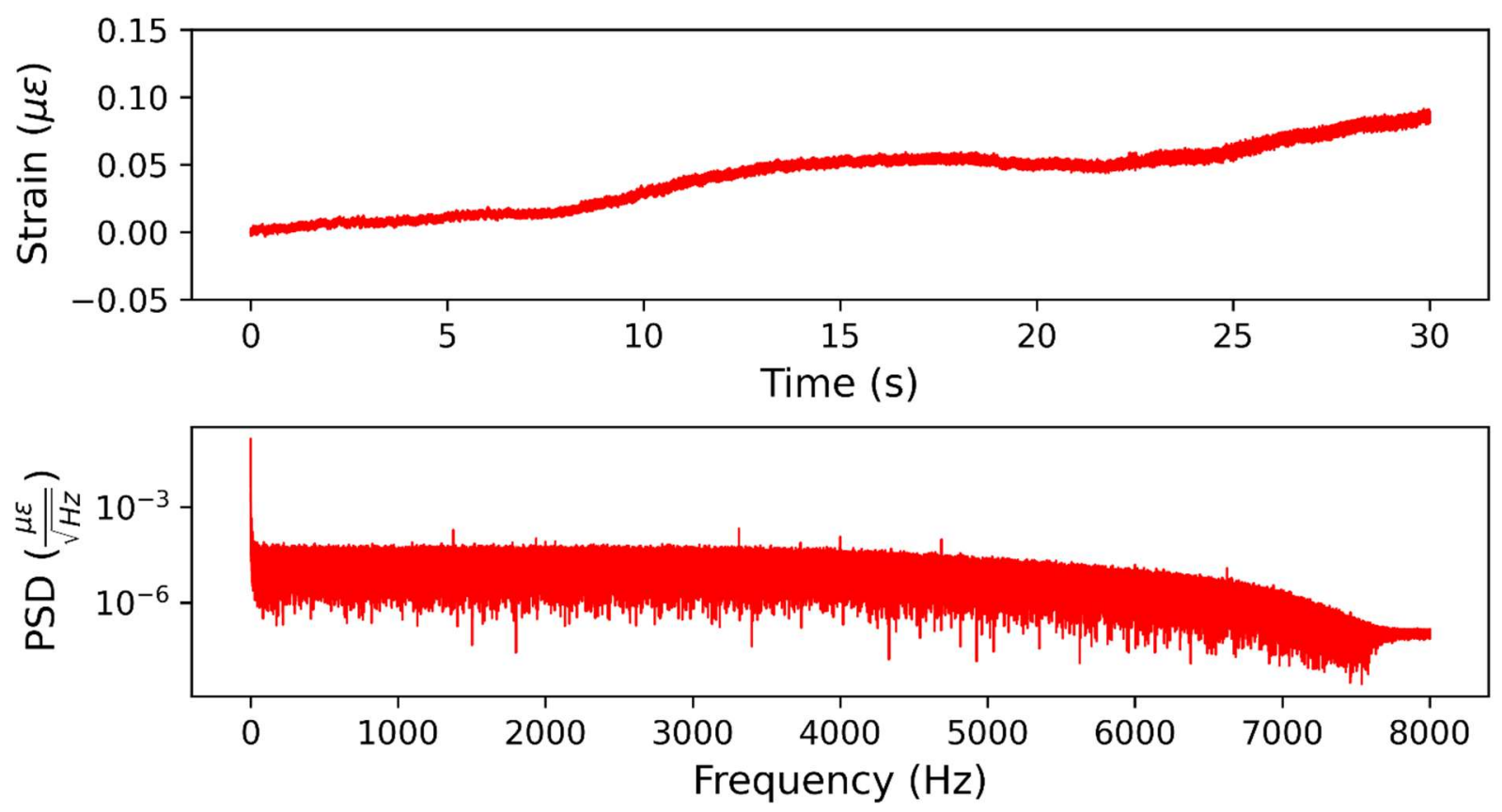

Figure 6. Unprocessed time-series and power spectral density plots of 30 seconds of $\varphi$-OTDR data acquired from within the pavement at the sampling rate of $32 \mathrm{KHz}$ when nothing is happening on the road surface.

The $\varphi$-OTDR data is post-processed using two steps. First, it is decimated. This process includes the application of an antialiasing filter and then down sampling to a rate of $40 \mathrm{~Hz}$. A Butterworth digital high-pass filter is applied in post-processing to the measurements with a $-3 \mathrm{~dB}$ point of 0.08 Hz. A Butterworth filter was chosen because of its minimal ripple characteristic in the passband. The strain measurements made are therefore minimally affected by the application of this filter if their frequency components are within the passband of the filter. Fig. 7 shows the data after the decimation and filtering process. The strain scale for the time-series plot is $\pm 0.05 \mu \varepsilon(50 \mathrm{n} \varepsilon)$. The associated standard deviation of this data and statistical repeatability of the strain measurements is $\pm 0.002 \mu \varepsilon(2 \mathrm{n} \varepsilon)$. This is three orders of magnitude less than the reported value for the commercial OFDR system, as described in the previous section. The dynamic noise floor is shown as $10^{-3} \frac{\mu \varepsilon}{\sqrt{H z}}$ for signals near DC, and $10^{-4} \frac{\mu \varepsilon}{\sqrt{H z}}$ for signals at $10 \mathrm{~Hz}$. 

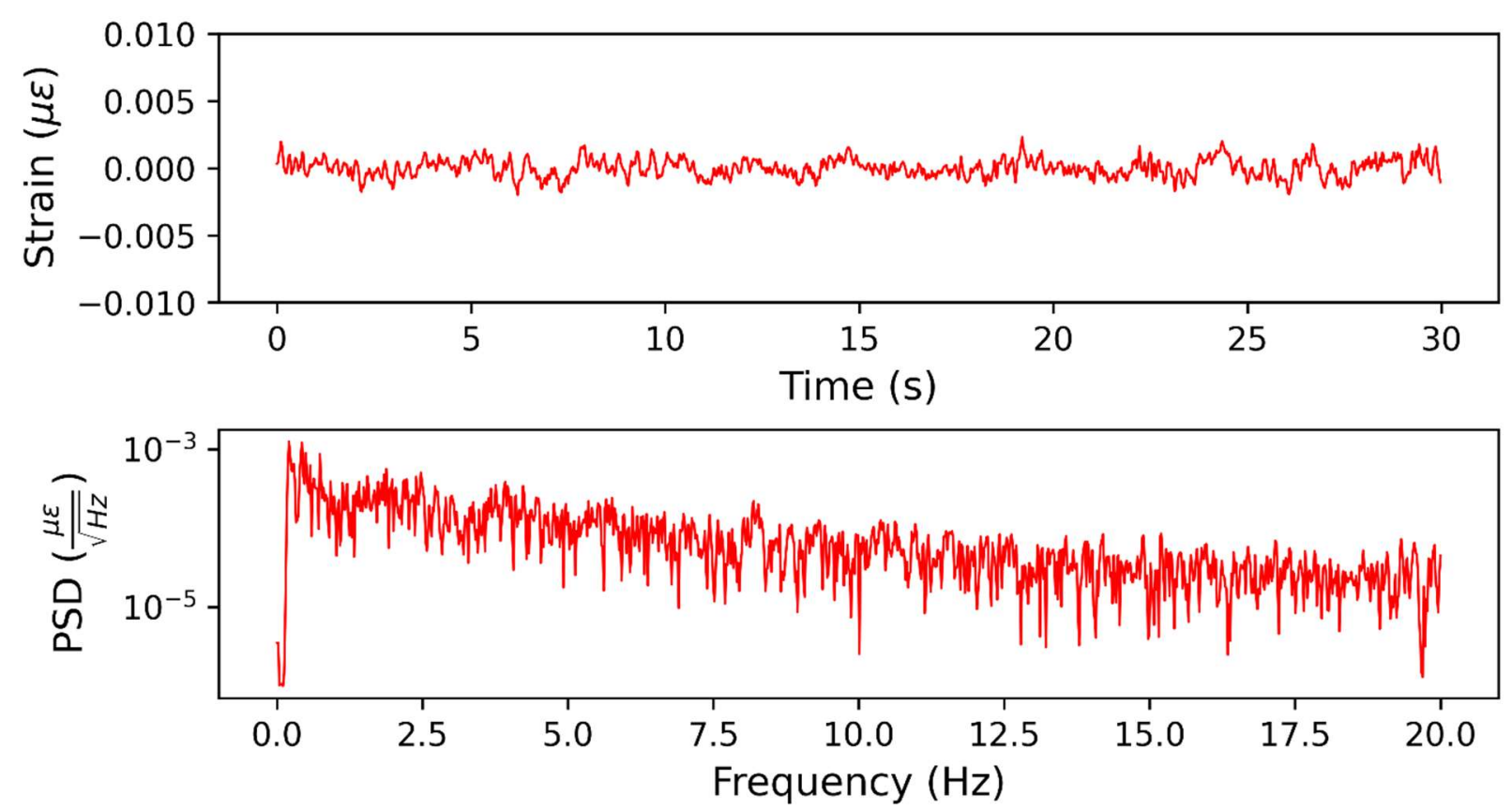

Figure 7. Time-series and power spectral density plots of 30 seconds of $\varphi$-OTDR data acquired from within the pavement that has been post-processed by decimating the data to a new sampling rate of $80 \mathrm{~Hz}$ and high-pass filtering the data using a digital Butterworth filter with a $-3 \mathrm{~dB}$ point of $0.08 \mathrm{~Hz}$.

\section{Validation of OFDR measurements using strain gauges}

Since OFDR measures strain over a very short distance ( $2.6 \mathrm{~mm}$ in this study), it can be compared with traditional strain gauges. The strain gauges that were installed into the pavement were oriented in the same direction as the fiber optic cables so that they would sense strain in the same direction. Figure 8 shows an example of the measurement consistency between strain gauges and OFDR. In this case, a sedan with a mass of $1,252 \mathrm{~kg}$ was parked with its front wheel over the location of a strain gauge and OFDR channel in the test road. After being parked for $250 \mathrm{~s}$, the sedan moved its wheel $1 \mathrm{~m}$ away from the strain gauge for $150 \mathrm{~s}$, before returning to its initial position. The OFDR measurements match well with the strain gauge measurements for both the loaded and unloaded condition, as well as the rebound between phases. 


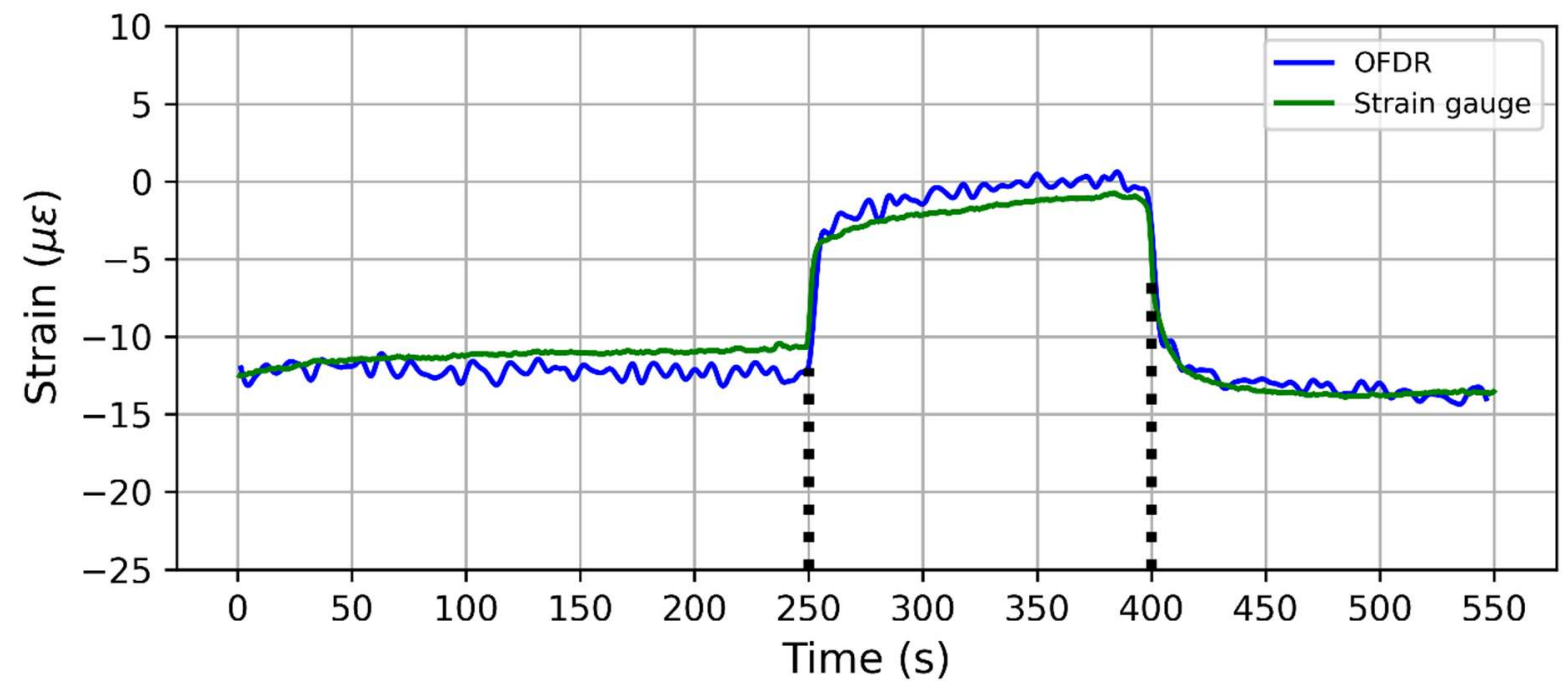

Figure 8. Comparison of Wheatstone bridge strain gauge measurements with OFDR measurements while a sedan's front wheel was parked on top of the collocated strain gauge and OFDR channel, removed for $150 \mathrm{~s}$ and then replaced. The black dotted lines indicate the time period where the wheel was removed from the strain gauge and OFDR channel position.

Since strain gauges are discrete measurements points, they are not effective for comparison with a spatial measurement technology like $\varphi$-OTDR. Since $\varphi$-OTDR measures strain over $2.04 \mathrm{~m}$, other mechanisms such as transitions from compression to tension away from wheels influence the measurements. For this reason, strain gauges were used to validate OFDR, and in turn OFDR was used to compare with $\varphi$-OTDR in the next section.

\section{Truck loading experiments}

One length of $\varphi$-OTDR cable is used in the following sections. It is the length located $400 \mathrm{~mm}$ from the OFDR cable as indicated in Fig. 9. To verify the $\varphi$-OTDR measurements, comparisons with OFDR measurements were conducted for the case when a Ford F-350 pickup truck with a mass of $2,830 \mathrm{kgs}$ moved on the road surface. The first test was the truck performing a repeated stop-and-go every $2 \mathrm{~m}$ along the road. The second test was the truck moving at $0.5 \mathrm{~m} / \mathrm{s}$. The truck's front, road shoulder-side wheel was centered at approximately $750 \mathrm{~mm}$ from the edge of the road, which is the OFDR sensing cable location. The longitudinal location of the truck and its axles during the first stop-and-go test, as well as the lateral spacing during both tests are shown in the figure. 

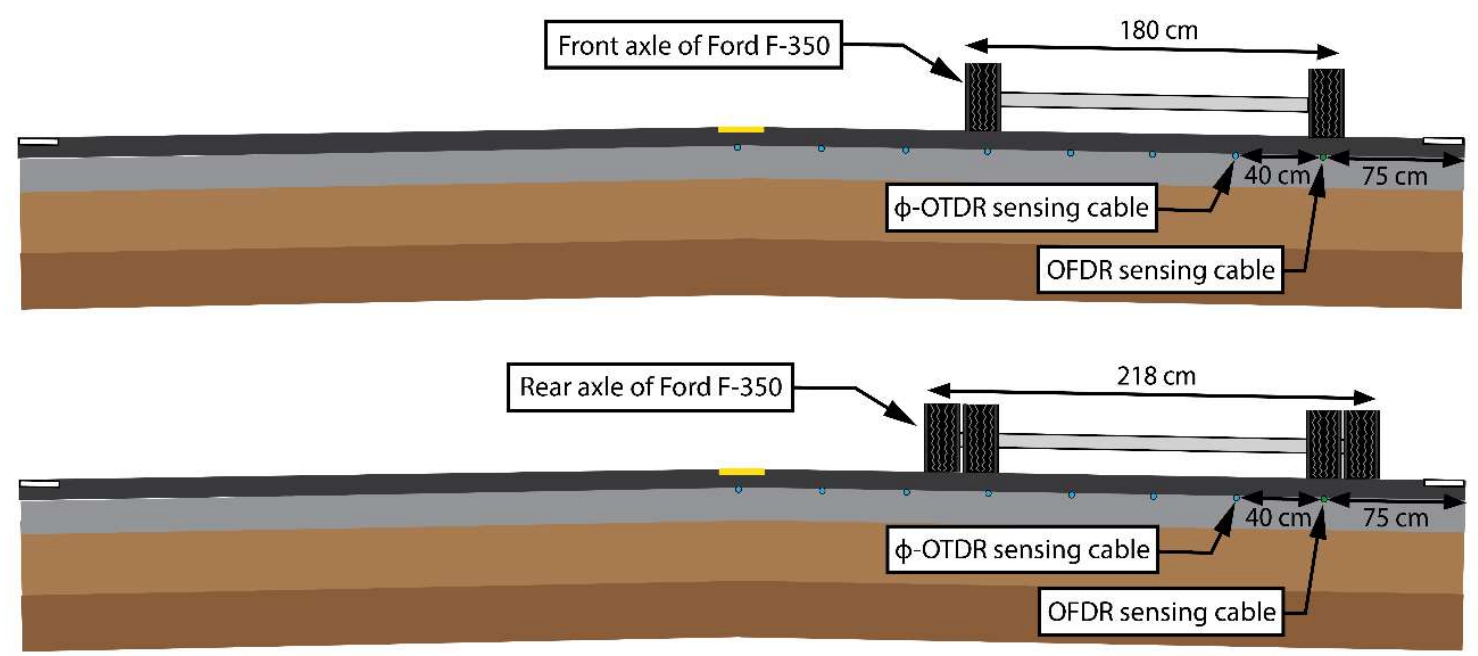

Figure 9. The location of the Ford F-350 pickup truck's axles on the test road relative to the sensing cable locations within the pavement. During the stop-and-go test, the truck was advanced down the road $2 \mathrm{~m}$ at a time and then stopped for $10 \mathrm{~s}$. The OFDR cable was located $75 \mathrm{~cm}$ from the road shoulder while the $\varphi-O T D R$ cable was located $115 \mathrm{~cm}$ from the shoulder. The F-350 had a dual rear axle, so the configuration is shown for both axles.

The truck was advanced down the road $2 \mathrm{~m}$ at a time, sitting for $10 \mathrm{~s}$ at each location. This allowed for the $\varphi$-OTDR data to be processed using the decimation and high pass filtering explained previously because the strain is dynamic, albeit at very low frequency. The measured strain values ( $\varepsilon=\Delta L / L$ ) vary with the gauge length $(L)$ of the two systems. In the case of the OFDR system, $L$ is $2.6 \mathrm{~mm}$, while for $\varphi$-OTDR it is $2.04 \mathrm{~m}$. Therefore, measurements are expected to be much lower for the $\varphi$-OTDR system when subject to the same deformation.

As shown in Fig. 9, the location of the cable for $\varphi$-OTDR measurement was different from that for OFDR measurement. To make a meaningful comparison, the pseudo static $\varphi$-OTDR and OFDR measurements were compared with 3D finite element (FE) modelling results when the F-350 pickup truck stopped along the road. The loading case was modelled using Abaqus finite element software. The roadway and underlying soils were modelled as 3D stress elements of type C3D8RH; an 8-node linear brick with hybrid formulation, constant pressure, reduced integration, and hourglass control. Fig. 10(a) shows the plan view of the top surface of the FE model indicating the locations of the $\varphi$-OTDR and OFDR cables relative to the truck wheel positions. The wheel positions are indicated by contours of longitudinal strain in the road under the truck's static load. Fig. 10(b) shows an isometric view of the full 3D FE model. The model was a cuboid $40 \mathrm{~m}$ long, $7.32 \mathrm{~m}$ wide and $15.68 \mathrm{~m}$ deep with 6 layers. The layers consisted of the four layers as shown in Fig. 2 (Section B-B') and an additional two layers of clay. The pavement's material properties were determined through consultation with a designing pavement engineer. The material properties and geometry of the saturated clay layers were determined from geotechnical exploration near the test site. The fully saturated clay was modelled in an undrained, constant 
volume condition (i.e., total stress analysis) because the testing was done relatively fast with limited excess pore pressure dissipation. The model's material parameters are shown in Table 1. Loading from the truck was applied on the model statically using four area loads: $0.0625 \mathrm{~m}^{2}$ for each front wheel and $0.1225 \mathrm{~m}^{2}$ for each double back wheel. Each wheel location was loaded with $6.33 \mathrm{kN}$. The mesh of the model was refined at the simulated truck locations to capture the localized deformation. The total number of elements was 917,280.

Table 1. Material Properties for Elastic Finite Element Analysis of Roadway

\begin{tabular}{|l|l|l|l|}
\hline Material & Thickness $(\mathrm{m})$ & Young's Modulus (MPa) & Poisson's Ratio \\
\hline New HMA & 0.03175 & 4500 & 0.33 \\
\hline Old HMA & 0.051 & 4700 & 0.33 \\
\hline AB Class 2 & 0.395 & 550 & 0.35 \\
\hline Cohesive Subgrade & 0.2 & 95 & 0.35 \\
\hline Clay-1 & 4.32 & 200 & 0.499 \\
\hline Clay-2 & 10.68 & 250 & 0.499 \\
\hline
\end{tabular}

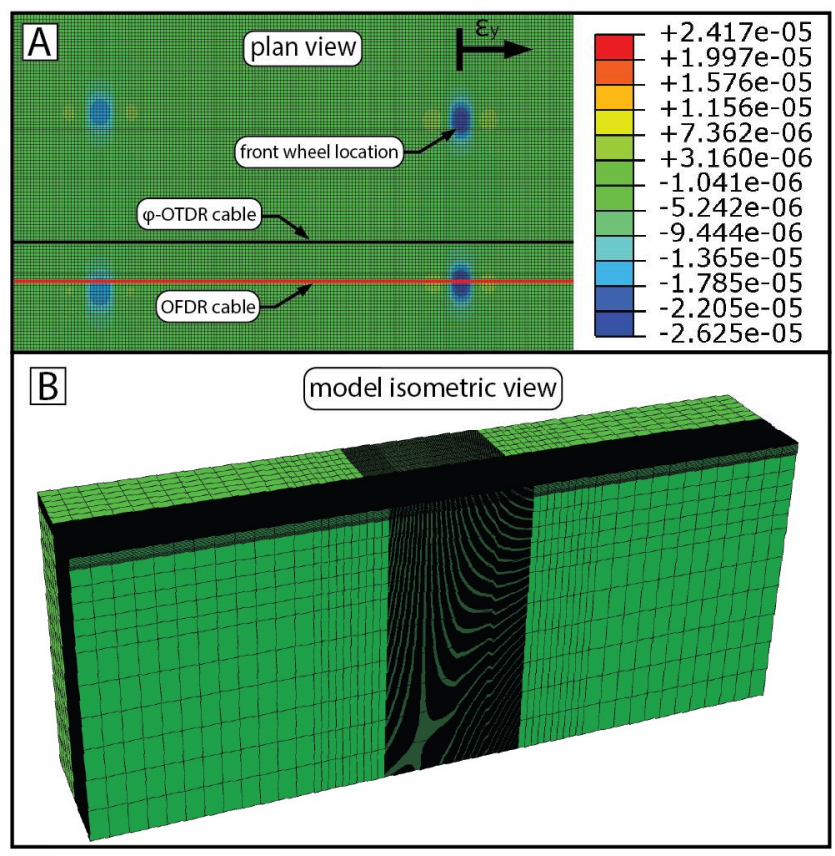

Figure 10. (a) Plan view of the 3D Abaqus FE model with contours of longitudinal strain in the road. The model was made of 917,280 C3D8RH stress elements and refined below the location statically loaded by the truck's weight. The $\varphi$-OTDR cable was $40 \mathrm{~cm}$ towards the center of the road relative to the OFDR cable, which was centered under the front wheel of the truck. (b) Isometric view of the $40 m \times 7.32 m \times 15.68 \mathrm{~m}$ cuboid FE model. 
The FE derived results are shown in Fig. 11 compared with actual measurements from the first stop-and-go test. Since the FE mesh was coarser than the $2.6 \mathrm{~mm}$ length over which OFDR measurements were taken, the OFDR measurements and nodal strains are compared directly in Fig. 11(top). Due to the high spatial readout of OFDR, the OFDR data appears as solid lines. There are compressive strains underneath each axle which transition to tensile strains on either side of the axles in both measured and simulated data. The spatial distribution of compressive strain is wider in the actual measured case using OFDR than in the simulation. This could be an effect of the steel-reinforced cable distributing strain along itself over a longer length than experienced by the pavement without the cables. The $\varphi$-OTDR measurements were compared by performing moving average of the calculated FE strain over the $2.04 \mathrm{~m}$ gauge length, as shown in Fig 11 (bottom). The $\varphi$-OTDR data has a spatial readout of every $1.02 \mathrm{~m}$, so it appears as discrete points. The $\varphi$-OTDR measurements and spatially averaged FE strain calculations match very well.

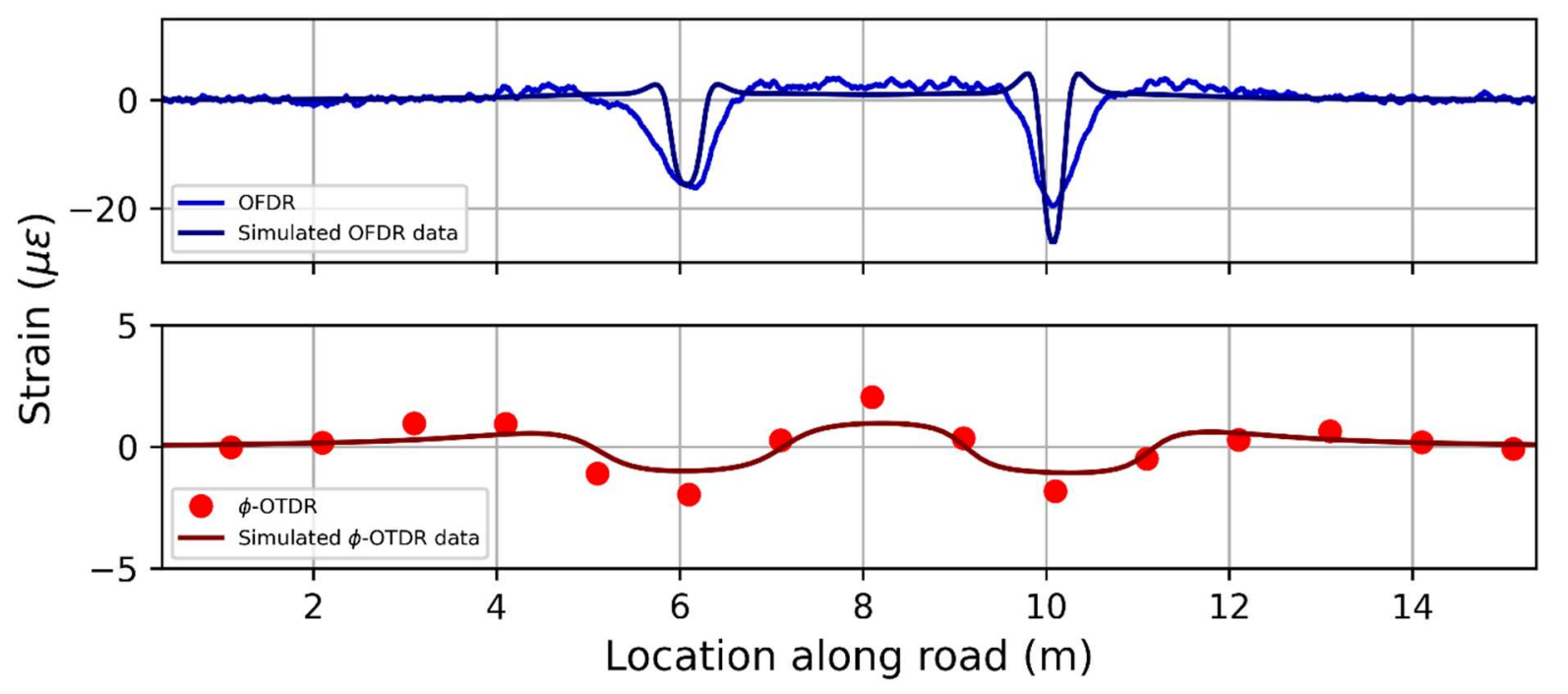

Figure 11. Results from the pseudo static verification test where the F-350 truck was stopped on the road for 10 seconds. Strain was measured using both OFDR and $\varphi$-OTDR and compared with the $3 D$ elastic $F E$ analysis for the same cable locations. The $\varphi-O T D R$ gauge length is simulated by averaging the FE analysis strain over $2.04 \mathrm{~m}$.

Although the cable locations are different, the OFDR and $\varphi$-OTDR measurements can be compared more directly by spatially averaging the OFDR measurements over the longer gauge length of $2.04 \mathrm{~m}$ such that:

$\varepsilon_{\varphi-\mathrm{OTDR}}(x) \cong \frac{1}{m+1} \sum_{n=-m / 2}^{m / 2} \varepsilon_{O F D R}\left(x+n L_{O F D R}\right)$

where $\varepsilon_{\varphi-0}$ is the strain measured with $\varphi$-OTDR, $\varepsilon_{\mathrm{OFDR}}$ is the strain measured with OFDR, $m+1$ is the number of OFDR measurements within one $\varphi$-OTDR measurement, and $L_{\text {OFDR }}$ is the length over which one OFDR measurement is made. 
This is a centered spatial moving average of the OFDR data at the gauge length of the $\varphi$-OTDR system. This relationship is shown in Fig. 12 for the case of the truck driving at $0.5 \mathrm{~m} / \mathrm{s}$ down the road. A discrete moment in time is shown when the trucks axles are at approximately 6 and $10 \mathrm{~m}$.

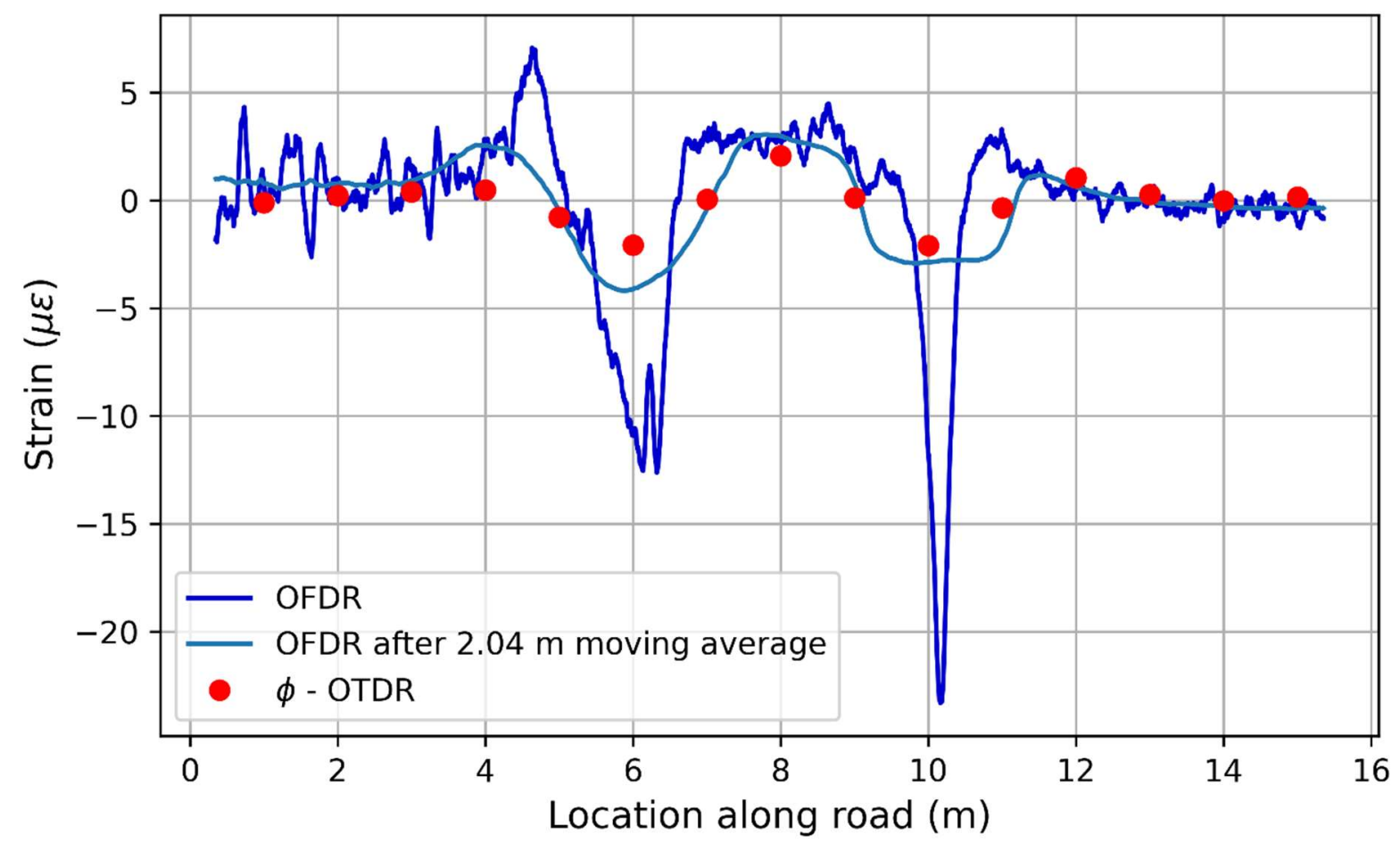

Figure 12. Results from the verification test where the F-350 truck was advanced down the road at $0.5 \mathrm{~m} / \mathrm{s}$. Strain was measured using both OFDR and $\varphi$-OTDR and the OFDR measurements were converted to equivalent $\varphi$-OTDR measurements using Eq 2. The cables were not at exactly the same location in the pavement (see Fig. 8), which is what the slight magnitude difference is attributed to.

The measurements of both OFDR and $\varphi$-OTDR can be best observed using an 2D plot that is similar to the waterfall diagram introduced in Fig. 4. However, rather than the pixel color corresponding to the FBE power, the pixel color corresponds to strain value. This type of plot is shown in Fig. 13 and compares the $\varphi$-OTDR measurements ((a) and (c)) with the spatially averaged OFDR measurements ((b) and (d)). The behavior of the truck can be clearly exhibited by both technologies including its speed and location. The locations where the truck stopped during the stop-and-go test can be identified by the portions of the graphs where the strain signal is not moving along the distance axis. Fig. 13(a) and (c) display the strain measurements in both time and space as an image that can be used to extract information graphically of the $\varphi$-OTDR data for the two loading cases (stop-and-go and $0.5 \mathrm{~m} / \mathrm{sec}$ ). Much like Fig. 4, the speed of the truck can be observed when it is in motion (the $0.5 \mathrm{~m} / \mathrm{sec}$ case) with $\varphi$-OTDR. The strain that the truck imparts on the road can be measured with $\varphi$-OTDR even when the truck is briefly still (the stop-and-go 
case). The time over which the truck can be stationary and continue to be observed with $\varphi$-OTDR is governed by the lowest frequency component that is left intact during the filtering process.

The comparisons within Fig. 13 also show that the value of the strain measurements made by OFDR are in good agreement with the $\varphi$-OTDR measurements. Once again, the magnitude of strain measured by OFDR is slightly higher due to its positioning directly under the wheel. The maximum compressive strain locations indicate the location of the axles. The value of this strain is typically $2.0 \mu \varepsilon$ for $\varphi$-OTDR and $3.5 \mu \varepsilon$ for OFDR. The regions of tensile strain in front of the truck, behind the truck and between the axles can be observed in both datasets. The resolution of the image created from the $\varphi$-OTDR data is less in the vertical direction because the spatial sampling of this data is one measurement every $1.02 \mathrm{~m}$. For this small-scale example the spatial sampling appears very coarse in comparison to the OFDR image, however this sampling in space proves effective for localizing the strain from the truck wheels.

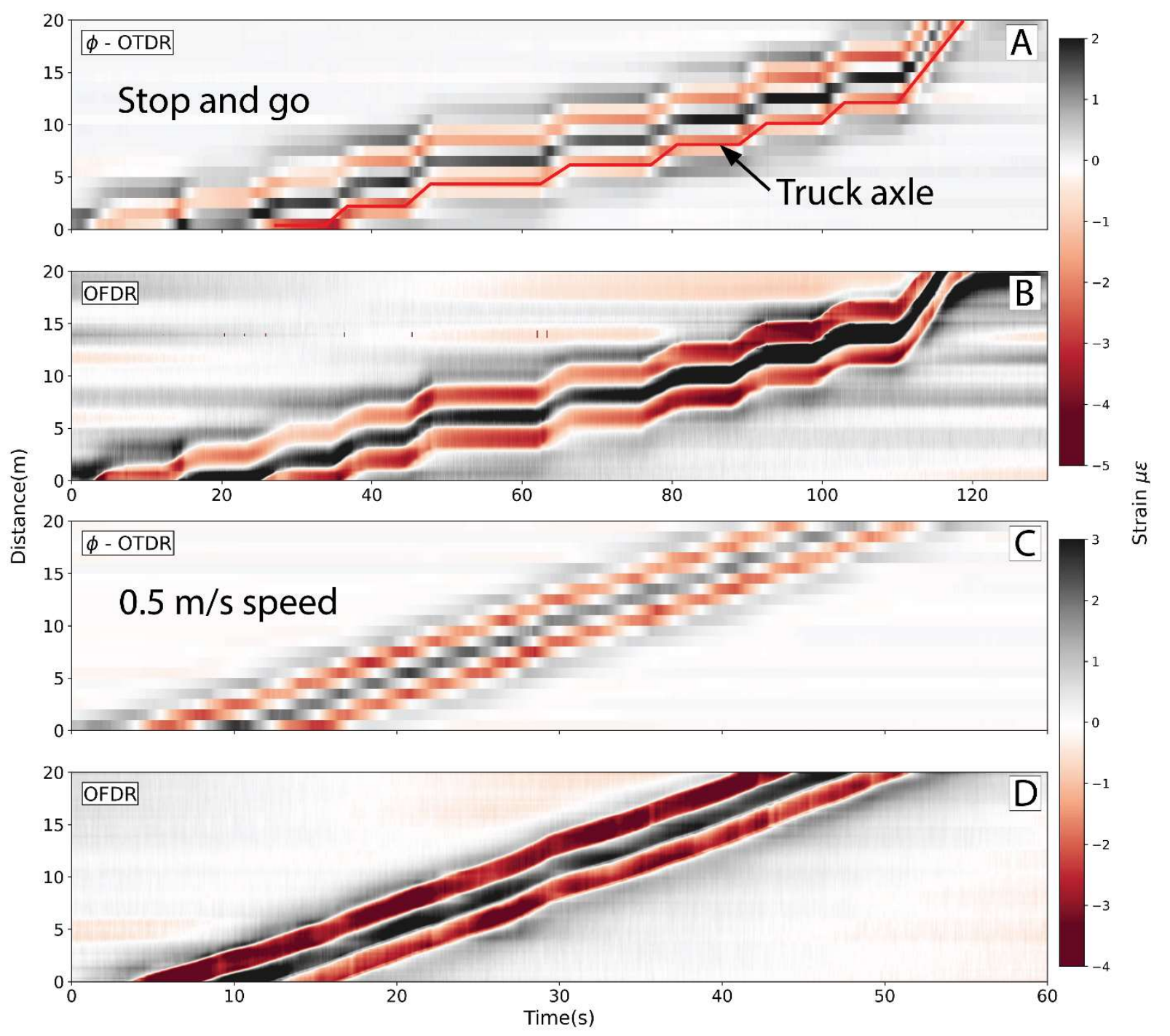

Figure 13. Strain amplitude images for both technologies during the verification tests. The sensing cables used are 75 and $115 \mathrm{~cm}$ from the road's shoulder for OFDR and $\varphi$-OTDR, respectively and 
embedded beneath $3.175 \mathrm{~cm}$ of AC. The truck's wheels were placed over the OFDR cable's location.

\section{Test cases of $\varphi$-OTDR sensitivity}

In the previous section, $\varphi$-OTDR has been demonstrated as capable of measuring longitudinal strain within pavement while a relatively large vehicle moved along the surface. The results shown in this section demonstrate the sensitivity of the embedded $\varphi$-OTDR installation to events of much smaller influence on the pavement. The strain measurement results are shown for a runner, pedestrian, bicyclist and finally a medium sized dog moving along the road. The measurements made by $\varphi$-OTDR for these test cases are shown in Fig. 14. No attempt was made to simulate these cases by a numerical model due to complex dynamic pavement-load interactions, which requires further study.

The runner induced a longitudinal compressive strain of $-0.4 \mu \varepsilon(-400 n \varepsilon)$ on the pavement over the $2.04 \mathrm{~m}$ gauge length of the $\varphi$-OTDR system. The footfall of the runner is clearly discernable as a train of impulses acting on the pavement. There is a short time when there is no contact between the runner and the pavement, which is evident in the strain measurements. The pedestrian was aways in contact with the pavement, which is why these breaks seen in the runner data do not exist for the pedestrian. The pedestrian also causes a smaller typical strain value of $-0.25 \mu \varepsilon(-250$ $n \varepsilon)$. This makes sense because the pedestrian does not impact the pavement with the same amount of vertical kinetic energy that the runner does. The cyclist induces a similar value of compressive strain to the pedestrian, about $-0.25 \mu \varepsilon(-250 \mathrm{n} \varepsilon)$. However, unlike the truck case shown in Fig. 13, both axles are not seen with bicycle because of the gauge length of the $\varphi$-OTDR system. The strain is measured over $2.04 \mathrm{~m}$ while the wheel spacing of the bicycle was $1.06 \mathrm{~m}$. Therefore, the location of both axles was always within one gauge length, making it impossible to see a region of decreased strain between them. Finally, the running dog demonstrates the extreme sensitivity of $\varphi$-OTDR to measure small strains within pavement. The dog ran along the pavement inducing a typical compressive strain of $-0.02 \mu \varepsilon(-20 \mathrm{n} \varepsilon)$ on the sensing fiber within the pavement.

This sensitivity study shows how $\varphi$-OTDR can be used to monitor the material behavior changes in pavement at exceedingly small strains and even possibly be used to detect and track events as small as an animal walking on the road. None of these events are below the noise floor of $2 \mathrm{n} \varepsilon$ demonstrated by Fig. 7. Even the case of the running dog exhibits a signal to noise ratio (SNR) of $17 \mathrm{~dB}$ defined as:

$S N R=10 \log \left(\left(\frac{A_{\text {signal }}}{A_{\text {noise }}}\right)^{2}\right)$

where $A_{\text {signal }}$ is the root-mean-square amplitude of the signal ( $14.1 \mathrm{n} \varepsilon$ for the $\operatorname{dog}$ ) and $A_{\text {noise }}$ is the root-mean-square amplitude of the noise ( $2 \mathrm{n} \varepsilon$ for the $\varphi$-OTDR system). This indicates that even much smaller strain events than the dog running can be reliably measured with $\varphi$-OTDR. 

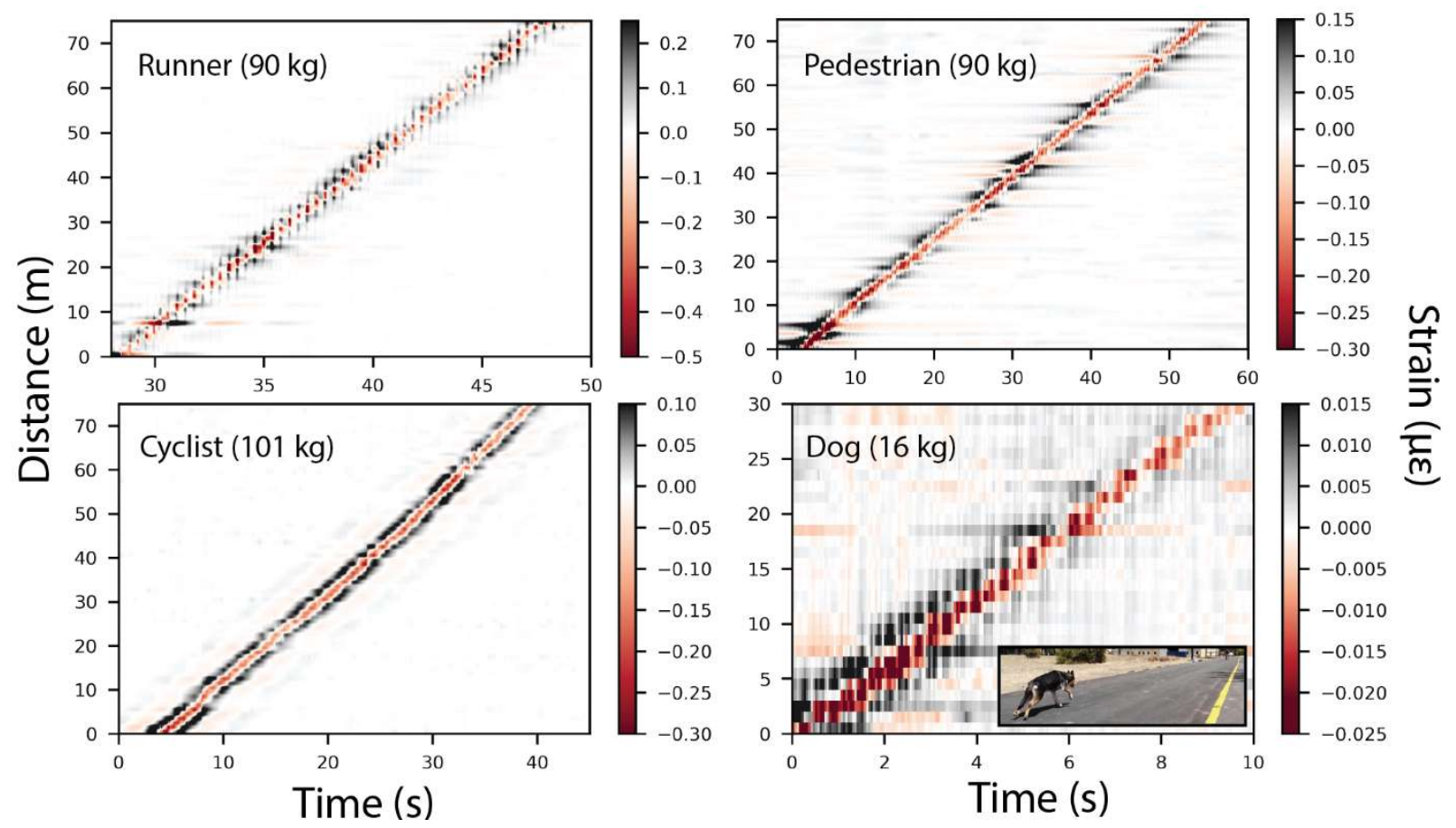

Figure 14. Strain amplitude images of the $\varphi-O T D R$ measurements made on the test road when a runner, pedestrian, cyclist, and dog moved along the road.

\section{Conclusions}

DFOS technologies provide the possibility to turn currently passive roadway systems into interactive surfaces much like the touchscreens on smartphones and tablets. $\varphi$-OTDR, also known as distributed acoustic sensing (DAS), has the benefit of an extremely long sensing range (10's of $\mathrm{km})$, phenomenally low noise floor ( $2 \mathrm{n} \varepsilon$ in this study), and exceptionally high acquisition rates (10's-100's of kHz). The deployment of DFOS in roadways, and particularly $\varphi$-OTDR depends on effective installation and mechanical understanding of the roadway systems being monitored. This paper presents an effective installation strategy for DFOS at the time of asphalt concrete pavement resurfacing. A new technique for monitoring dynamic strains in civil infrastructure, $\varphi$-OTDR, was deployed and validated using a well-accepted fiber optic technique, OFDR, as well as traditional pavement strain gauges.

$\varphi$-OTDR has the challenge of laser phase noise, which causes difficultly in monitoring lowfrequency or static strain. A simple technique for mitigating this problem is presented. The measurements made with $\varphi$-OTDR are then compared to results of 3D finite element modelling for the case of a static loading by a pickup truck on the test road. The $\varphi$-OTDR measurements are also compared with those made by OFDR. All data were consistent to each other. Finally, the low noise floor and extreme sensitivity of $\varphi$-OTDR is demonstrated by monitoring strain in the pavement caused by a more complex pavement-load interaction cases such as a runner, pedestrian, cyclist, and dog moving along the road. $\varphi$-OTDR is proven as a viable technique for monitoring 
very small strain in pavements that can be used to inform the understanding of pavement materials and monitor events that happen on asphalt surfaced roads.

\section{Acknowledgements}

This work was supported by the Center for Information Technology Research in the Interest of Society (CITRIS). The authors thank Angel Mateos, Irwin Guada and Fabian Paniagua of the University of California Pavement Research Center (UCPRC) for assisting to install the optical fiber. They further thank former UC Berkeley Assistant Dean of Engineering Scott Shackleton for helping facilitate the construction of the research facility used in this study. Many of the figures in this paper were created using Matplotlib 3.1. ${ }^{39}$

\section{References}

1. Hartog AH. An Introduction to Distributed Optical Fibre Sensors. CRC Press; 2017.

2. Posey R, Johnson GA, Vohra ST. Strain sensing based on coherent Rayleigh scattering in an optical fibre. Electronics Letters. 2000;36(20):1688. doi:10.1049/el:20001200

3. Ogden HM, Murray MJ, Murray JB, Kirkendall C, Redding B. Frequency multiplexed coherent $\varphi$-OTDR. Scientific Reports. 2021;11(1). doi:10.1038/s41598-021-97647-z

4. Taylor HF, Lee CE. Apparatus and method for fiber optic intrusion sensing. March 1993.

5. Russell S, Hayward JPW, Lewis AB. Acoustic sensing using an optical fibre. April 2011.

6. Masoudi A, Belal M, Newson TP. A distributed optical fibre dynamic strain sensor based on phase-OTDR. Measurement Science and Technology. 2013;24(8):085204.

doi:10.1088/0957-0233/24/8/085204

7. Alekseev AE, Vdovenko VS, Gorshkov BG, Potapov VT, Simikin DE. A phase-sensitive optical time-domain reflectometer with dual-pulse phase modulated probe signal. Laser Physics. 2014;24(11):115106. doi:10.1088/1054-660x/24/11/115106

8. Daley TM, Miller DE, Dodds K, Cook P, Freifeld BM. Field testing of modular borehole monitoring with simultaneous distributed acoustic sensing and geophone vertical seismic profiles at Citronelle, Alabama. Geophysical Prospecting. 2015;64(5):1318-1334.

doi:10.1111/1365-2478.12324

9. Ajo-Franklin JB, Dou S, Lindsey NJ, et al. Distributed acoustic sensing using dark fiber for near-surface characterization and broadband seismic event detection. Scientific

Reports. 2019;9(1). doi:10.1038/s41598-018-36675-8

10. Giallorenzi TG, Sigel GH, Bucaro JA. Optical Fiber Sensor Technology. Optical Fiber Communication. 1982;18(4):626-665. doi:10.1364/ofc.1982.thgg1 
11. Loayssa A, Sagues M, Eyal A. Phase noise effects on phase-sensitive OTDR sensors using optical pulse compression. Journal of Lightwave Technology. 2021.

doi:10.1109/jlt.2021.3138249

12. Hall AJ, Minto C. Using fibre optic cables to deliver intelligent traffic management in Smart Cities. International Conference on Smart Infrastructure and Construction 2019 (ICSIC). 2019. doi:10.1680/icsic.64669.125

13. Liu H, Ma J, Xu T, Yan W, Ma L, Zhang X. Vehicle detection and classification using distributed fiber optic acoustic sensing. IEEE Transactions on Vehicular Technology. 2020;69(2):1363-1374. doi:10.1109/tvt.2019.2962334

14. Lindsey NJ, Yuan S, Lellouch A, Gualtieri L, Lecocq T, Biondi B. City-scale dark fiber das measurements of infrastructure use during the COVID-19 pandemic. Geophysical Research Letters. 2020;47(16). doi:10.1029/2020g1089931

15. Zhang CC, Shi B, Zhu HH, Wang BJ, Wei GQ. Toward distributed fiber-optic sensing of subsurface deformation: A theoretical quantification of ground-borehole-cable interaction. Journal of Geophysical Research: Solid Earth. 2020;125(3). doi:10.1029/2019jb018878

16. Inaudi D, Glisic B. Long-range pipeline monitoring by distributed fiber optic sensing. Journal of Pressure Vessel Technology. 2009;132(1). doi:10.1115/1.3062942

17. Di Murro V, Pelecanos L, Soga K, Kechavarzi C, Morton RF, Scibile L. Long-term deformation monitoring of CERN concrete-lined tunnels using distributed fibre-optic sensing. Geotechnical Engineering Journal of the SEAGS \& AGSSEA. 2019;50(2).

18. Mohamad H, Soga K, Pellew A, Bennett PJ. Performance monitoring of a secant-piled wall using distributed fiber optic strain sensing. Journal of Geotechnical and Geoenvironmental Engineering. 2011;137(12):1236-1243. doi:10.1061/(asce)gt.19435606.0000543

19. Kechavarzi C, Pelecanos L, Soga K. Distributed fibre optic sensing for monitoring reinforced concrete piles. Geotechnical Engineering Journal of the SEAGS \& AGSSEA. $2019 ; 50(1)$

20. Hu T, Hou G, Li Z. The field monitoring experiment of the roof strata movement in coal mining based on Dfos. Sensors. 2020;20(5):1318. doi:10.3390/s20051318

21. Hubbard PG, Xu J, Zhang S, et al. Dynamic Structural Health Monitoring of a model wind turbine tower using distributed acoustic sensing (das). Journal of Civil Structural Health Monitoring. 2021;11(3):833-849. doi:10.1007/s13349-021-00483-y

22. FHWA. Table HM-12 - highway statistics 2020 - policy: Federal Highway Administration. U.S. Department of Transportation/Federal Highway Administration. https://www.fhwa.dot.gov/policyinformation/statistics/2020/hm12.cfm. Published October 2021. Accessed December 30, 2021. 
23. Holtz RD, Kovacs WD, Sheahan TC. An Introduction to Geotechnical Engineering. Pearson; 2011.

24. AASHTO. AASHTO Guide for Design of Pavement Structures: 1993. American Association of State Highway and Transportation Officials; 1993.

25. AASHTO. Mechanistic-Empirical Pavement Design Guide: A Manual of Practice. American Association of State Highway and Transportation Officials; 2020.

26. Xue W, Wang D, Wang L. A Review and Perspective about Pavement Monitoring. International journal of pavement research and technology. 2012;5(5):295-302. doi:http://www.ijprt.org.tw/reader/pdf.php?id=250

27. Tran VP, Tran TS, Lee HJ, Kim KD, Baek J, Nguyen TT. One stage detector (RetinaNet)-based crack detection for asphalt pavements considering pavement distresses and surface objects. Journal of Civil Structural Health Monitoring. 2020;11(1):205-222. doi:10.1007/s13349-020-00447-8

28. Sebaaly P, Tabatabaee N, Kulakowski B, Scullion T. Vol 1. McLean, VA: U.S. Department of Transportation: Federal Highway Administration; 1991:1-285.

29. Huhtala M, Alkio R, Pihljamaki J, Pienmaki M, Halonan P. Behavior of bituminous materials under moving wheel loads (with discussion). Journal of the Association of Asphalt Paving Technologists. 1990;59:422-442.

30. Zafir Z, Siddharthan R, Sebaaly PE. Dynamic pavement-strain histories from moving traffic load. Journal of Transportation Engineering. 1994;120(5):821-842. doi:10.1061/(asce)0733-947x(1994)120:5(821)

31. Bayat A, Knight MA, Soleymani HR. Field monitoring and comparison of thermal- and load-induced strains in asphalt pavement. International Journal of Pavement Engineering. 2012;13(6):508-514. doi:10.1080/10298436.2011.577776

32. Gokhale S, Byron T, Iyer S, Choubane B. Evaluation of pavement strain gauge repeatability. Transportation Research Record: Journal of the Transportation Research Board. 2009;2094(1):30-40. doi:10.3141/2094-04

33. Kara De Maeijer P, Van den bergh W, Vuye C. Fiber Bragg grating sensors in three asphalt pavement layers. Infrastructures. 2018;3(2):16.

doi:10.3390/infrastructures3020016

34. Mustafa S, Sekiya H, Maeda I, Takaba S, Hamajima A. Identification of external load information using distributed optical fiber sensors embedded in an existing road pavement. Optical Fiber Technology. 2021;67:102705. doi:10.1016/j.yofte.2021.102705

35. Pelecanos L, Soga K, Elshafie MZ, et al. Distributed fiber optic sensing of axially loaded bored piles. Journal of Geotechnical and Geoenvironmental Engineering. 2018;144(3):04017122. doi:10.1061/(asce)gt.1943-5606.0001843 
36. Glisic B, Chen J, Hubbell D. Streicker bridge: A comparison between Bragg-grating long-gauge strain and temperature sensors and Brillouin scattering-based distributed strain and temperature sensors. SPIE Proceedings. 2011. doi:10.1117/12.881818

37. Lv Y, Wang P, Wang Y, et al. Eliminating phase drift for distributed optical fiber acoustic sensing system with empirical mode decomposition. Sensors. 2019;19(24):5392. doi:10.3390/s 19245392

38. Crickmore R, Ku E. United States Patent 10,247,584. April 2019.

39. Hunter JD. Matplotlib: A 2D graphics environment. Computing in Science \& Engineering. 2007;9(3):90-95. doi:10.1109/mcse.2007.55 